\title{
PERFORMANCE ANALYSIS OF VAPOUR COMPRESSION REFRIGERATION SYSTEM BY USING R134A AND BLEND OF R290 AND R600A
}

\author{
Saurabh P. Kalambate ${ }^{1 *}$, Rajaram N. Gawade ${ }^{2}$, Shailesh B. Khandekar ${ }^{3}$, Dasharath D. Jadhav ${ }^{4}$, Naveed M.H. \\ Bhatkar $^{5}$ \\ *1,2,3,4,5 Department of Mechanical Engineering, Mumbai University, India \\ *1kalambate456@gmail.com; ${ }^{2}$ gawade.rajaram04@gmail.com, ${ }^{3}$ shaileshbkhandekar@gmail.com; \\ ${ }^{4}$ dasharathjadhav26@gmail.com; ${ }^{5}$ nvdbhtkr@gmail.com
}

*Corresponding Author: -

Email: kalambate456@gmail.com

\begin{abstract}
: -
In present scenario, most of the industrial and domestic refrigerators working on vapour compression refrigeration cycle are equipped with R134a as a refrigerant. R134a is having zero ozone depletion potential, but it has high global warming potential of 1300. Hence there is need identified for alternative refrigerant to R134a. This research work is focused on performance analysis of vapour compression refrigeration system with regard to COP, refrigerating effect, compressor work for two refrigerants i.e., R134a and blend of R290 and R600a in the proportion of $60 \%+40 \%$ respectively as an alternative refrigerant. Performance measure like compressor discharge temperature is also considered for analysis. The results of blend of $R 290$ and R600a are compared with halogenated hydrocarbon R134a. Trials are conducted for R134a and blend of $R 290$ and R600a. Results showed that COP for R134a refrigerant increases with decreases in evaporator temperature and for blend of $R 290$ and R600a it tries to remain constant. The maximum value of COP achieved for R134a and blend $R 290$ and $R 600 a$ are 3.11 and 4.09 respectively.
\end{abstract}

Keywords: - "Vapour Compression Refrigeration, R290, R600a, R134a, COP, refrigerating effect”

\section{(c) $(\$)$}




\section{INTRODUCTION}

Considering today's global environmental conditions, the ozone depleting potential (ODP) and Global warming potential (GDP) is becoming key criteria in the development of new refrigerant. In addition to this, it is also necessary to see that refrigerant gives maximum cooling effect in minimum power consumption. In present situation most of the refrigerating devices used in domestic and industrial applications working on vapour compression refrigeration cycle are equipped with R134a (Hydro fluorocarbon i.e., HFC) as a refrigerant. R134a is having zero ozone depletion potential but it has a high global warming potential o 1300 . Hence there is a need to identify alternative refrigerant for replacement of R134a.

Mohanraj et al. [4] investigate experimentally use of hydrocarbon refrigerant mixture (R290 and R600a by a weight ratio of 45.2:54.8) as an alternative refrigerant to R134a in domestic refrigerator. The testing was carried out continuously under different ambient temperature $\left(24,28,32,38\right.$ and $\left.43^{\circ} \mathrm{C}\right)$ and cycling test (ON/OFF) was carried at $32^{\circ} \mathrm{C}$ ambient temperature. The values of energy consumption for hydrocarbon mixture are shown low in the results. Macline-Cross [1] shown that hydrocarbon refrigerant reduces energy consumption by $20 \%$ instead of halogenated refrigerants such as R134a, R12. Fatouh et al. [3] had shown that performance of hydrocarbon such as propane (R290) and isobutene had equal performance as that of R134a. Baskaran et al. [5] analyzed vapour compression refrigeration system with different mixture of refrigerants such as R152a, R170, R600a, and R290 at various mass fractions. At condensation temperature at $50^{\circ} \mathrm{C}$ and evaporator temperature between $-30^{\circ} \mathrm{C}$ and $10^{\circ} \mathrm{C}$ the alternative refrigerants such as R152a, R290 at $29 \%$ and $71 \%$ respectively have slightly higher performance than R134a. Dongsoo Jung et al. [2] had reported that the mixture of propane/isobutane at the mass fraction of 0.6 of propane has $3 \pm 4 \%$ higher energy efficiency and faster cooling rate than R12.

The purpose of carrying out this research work is to characterize the performance of vapour compression refrigeration cycle for refrigerants R134a and blend of R290 and R600a in the proportion of 60\%+40\% respectively as an alternative refrigerant to replace R134a. Parameters considered for comparing the performance involves coefficient of performance (COP), refrigerating effect, compressor work, compressor discharge temperature and volumetric cooling capacity (VCC). In addition to this, the effect of different evaporator and condenser temperature on above mentioned performance parameters is also reported for both the refrigerants.

\section{Working of Vapor Compression Refrigeration System}

The most commonly used refrigeration system in refrigerators is vapour compression refrigeration system. The working fluid mentioned in the system is in the state of liquid and vapour. The requirement of the working fluid is that it should readily evaporate and condense i.e. the fluid should change it's state between vapour and liquid without leaving the system. Fig. below shows the vapour compression refrigeration system. The main parts of the system are compressor, condenser, expansion device, and evaporator.

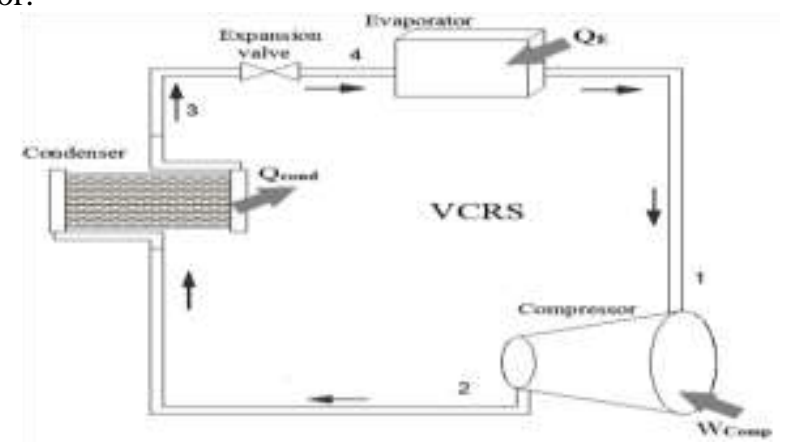

Fig. 1 working of vapor compression refrigeration system [6]

The refrigerant enters the compressor at the low temperature and pressure and gets compressed. Then it is compressed isentropically to attain higher temperature and pressure. Then this high temperature and pressure vapour enters the condenser. There it is condensed and brought to low temperature but the pressure remains high. Here the state of the refrigerant is changed from vapour to liquid. And this high pressure liquid flows towards the expansion device. In the expansion device the pressure of the liquid refrigerant decreases and finally the refrigerant becomes of low temperature and pressure. Then this refrigerant is passed through the evaporator where it absorbs the heat from the space, which is to be cooled, and turns back to the vapour state. This refrigerant is sucked by the compressor and the cycle gets repeated. Here refrigerant is cooled to low temperature than the atmosphere as to remove the heat from the region to be cooled and maintain the region for the same temperature.

\section{Experimental Setup}

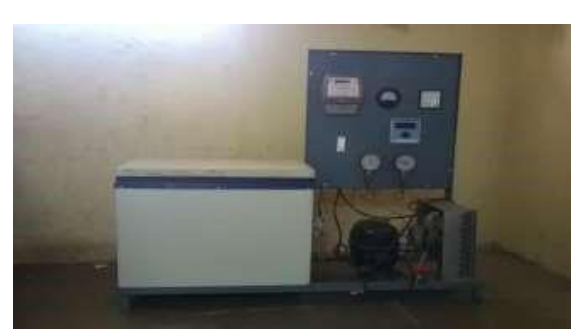

Fig. 2 Experimental Setup 
For carrying out this research work, refrigeration test rig was designed and fabricated as shown in fig. 2. The test rig consists of a compressor, air cooled condenser, thermostatic expansion valve (Capillary tube) and an evaporator. The compressor used is a hermetically sealed reciprocating compressor. A serpentine coil finned tube air cooled heat exchanger is used as condenser and is made up of copper. Condenser is cooled using fan. The evaporator is in the type of cylindrical spiral coil shape and made up of the copper. The Bourdon tube pressure gauges are used to measure pressure at compressor inlet and outlet. K type thermocouple is used to measure the temperature at various locations such as condenser inlet (T1), condenser outlet (T2), evaporator inlet (T3) and evaporator outlet (T4). Energy meter is used to measure the power consumption of the compressor. After carrying out leak testing of the test rig, refrigerant R134a was charged into the test rig and trial was conducted. Then test rig was properly evacuated using vacuum pump, and blend of refrigerant R290 and R600a was charged for conducting the trial.

\section{Results and Discussion}

The main purpose of this research work is to compare the performance of vapour compression refrigeration system for refrigerant R134a and blend of R290 and R600a as an alternative refrigerant. The testing was carried out on the vapour compression refrigeration test rig for both the refrigerants. The performance measures such as coefficient of performance (COP), Refrigerating effect and Compressor work are considered for analysis. The results of the tests conducted are plotted and shown below:

\section{A. Results of trial with R134a}

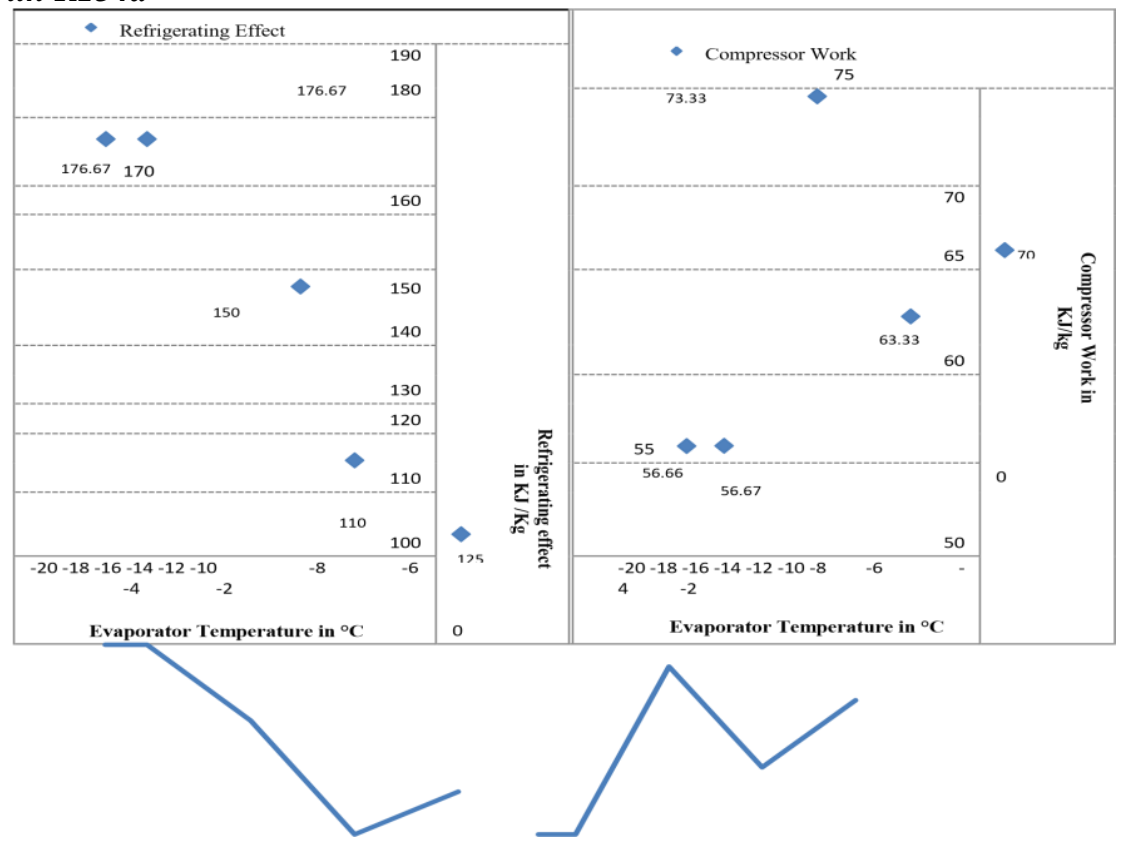

Fig. 3 Evaporator temperature vs Refrigeration effect

Fig. 4 Evaporator temperature vs Compressor work

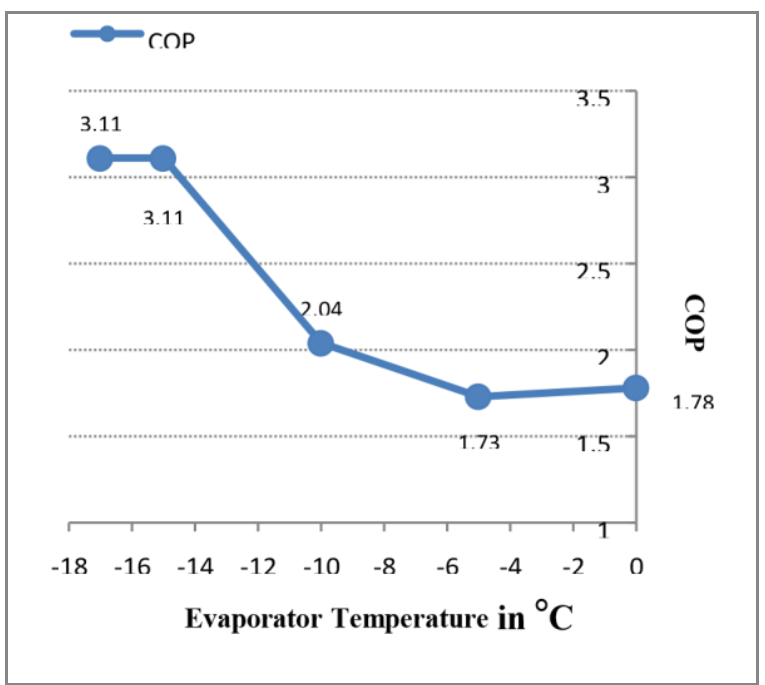

Fig. 5 Evaporator temperature vs COP 
Fig. 3, 4 and 5 shows variation of refrigerating effect, compressor work, COP against evaporator temperature respectively for refrigerant R134a. From figures it is observed that, COP and refrigerating effect increases with decrease in evaporator temperature and compressor work shows fluctuating trend with decrease in evaporator temperature. The maximum value of COP achieved with refrigerant R134a is 3.11 at evaporator temperature $-18{ }^{\circ} \mathrm{C}$.

\section{B. Results of trial with blend of R290 and R600a}

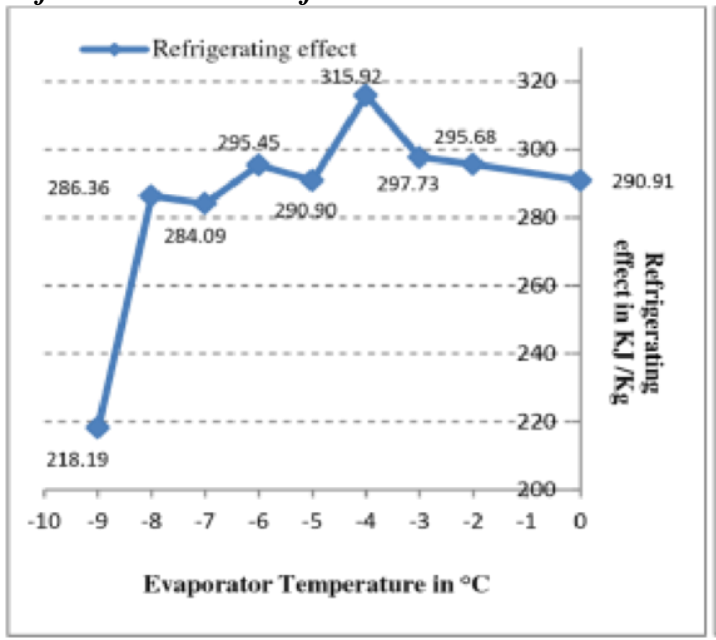

Fig. 6 Evaporator temperature vs Refrigeration effect

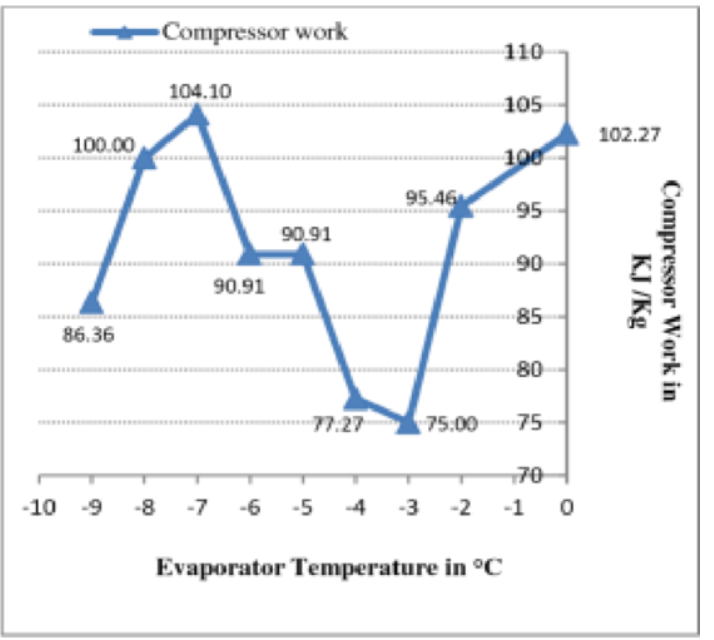

Fig. 7 Evaporator temperature vs Compressor work

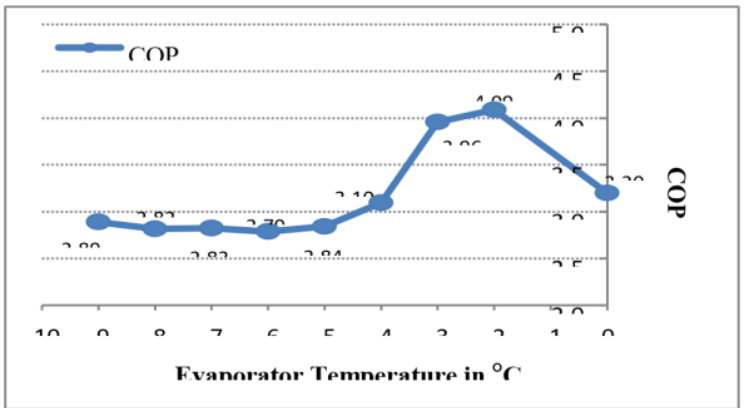

Fig. 8 Evaporator temperature vs COP

Fig. 6, 7 and 8 shows variation of refrigerating effect, compressor work, COP against evaporator temperature respectively for refrigerant as a blend of R290 and R600a. From figures it is observed that, COP tries to remain constant beyond -5 ${ }^{\circ} \mathrm{C}$. Refrigerating effect decreases with decrease in evaporator temperature beyond $-5{ }^{\circ} \mathrm{C}$ and compressor work shows fluctuating trend with decrease in evaporator temperature. The maximum value of $\mathrm{COP}$ achieved with blend refrigerant is 4.09 at evaporator temperature $-2{ }^{\circ} \mathrm{C}$. Blend refrigerant shows better performance in terms of COP than $\mathrm{R} 134 \mathrm{a}$ refrigerant.

\section{Conclusion}

The main focus of this research paper is to compare the performance of R134a and blend of R290 and R600a in the proportion of $60 \%+40 \%$ respectively. From the Results it is concluded that,

- For evaporator temperature in the range of $0{ }^{\circ} \mathrm{C}$ to $-5^{\circ} \mathrm{C}$ the blend of $\mathrm{R} 290$ and R600a refrigerant shows better performance in terms of COP.

- For the evaporator temperature beyond $-5^{\circ} \mathrm{C}$, refrigerant $\mathrm{R} 134 \mathrm{a}$ shows better performance.

- Therefore, the blend of R290 and R600a can replace refrigerant R134a for the evaporator temperature ranging from $0^{\circ} \mathrm{C}$ to $-5^{\circ} \mathrm{C}$.

Beyond $-5^{\circ} \mathrm{C}$ temperatures, the performance of blend refrigerant is not satisfactory this can be attributed to variation in the properties as well as high compression pressure required as compared to refrigerant R134a. Even though R134a has higher Values of COP for lower evaporator temperature it has got harmful effects on the environment. Hence the use of blend refrigerant is preferred with proper selection of compressor in order to have adequate compression pressures.

\section{References}

[1] Maclaine-Cross.I.L (1997), “Why hydrocarbons save energy”, AIRAH Journal, June1997,Vol.51, pp.33-37.

[2] Dongsoo Jung, Chong-Bo Kim, Kilhong Song, Byoungjin Park (2000) "Testing of propane/isobutene mixture in domestic Refrigerators", International Journal of Refrigeration Vol.23 pp.517-527.

[3] Fatouh.M and El Kafafy.M (2006), "Assessment of propane/commercial isobutene mixtures as possible alternatives to $R-134 a$ in domestic refrigerators", Energy conversion and management, Vol.47, pp.2644-2658. 
[4] Mohanraj.M, Jayaraj.S, Muraleedharan.C and Chandrasekar.P (2009) "Experimental investigation of R290/R600a mixture as an alternative to $R-134 a$ in a domestic refrigerator", International Journal of Thermal Sciences Vol.48, pp.1036-1042.

[5] Baskaran.A and Koshy Mathews.P (2012) "A Performance comparison of vapour compression refrigeration system using various alternative refrigerants", International Journal of Scientific and Engineering Research, Vol.3 No.10, pp.1-

[6] P.Thangavel, Dr.P.Somasundaram, T.Sivakumar, C.Selva Kumar, G.Vetriselvan(2013) "Simulation Analysis of Compression Refrigeration Cycle with Different Refrigerants" International Journal of Engineering and Innovative Technology (IJEIT) Volume2, pp.127-130 